\title{
The Aesthetics of Representation: Dramatic Texts and Dramatic Engagement
}

\section{Staking the Territory}

There are several ways in which aesthetic discourses might be positioned in the field of drama education. While some might locate "aesthetics" in the cognitive or interpretive realm of learning, and others the affective or philosophical realm, I have chosen to speak of the discourses of aesthetics as they relate to both cognitive and embodied responses to the (extra)ordinary events of a drama classroom. I am already unsatisfied with the recognizable distinctions implied in this binary, but I persist in the hope that the relationship between these learning functions will become clear as I proceed with what I have termed the sociology of aesthetics in drama practice. In drama, we attemptcollectively- to represent our lives through art as we come to know the world and our sensuous responses to it.

Fenner's (2003) brief history of aesthetic experience and aesthetic analysis will further help stake the territory about which we are speaking in a drama classroom. Calling aesthetic experiences the 'raw data' that aesthetics is meant to explain, he helpfully distinguishes between Kantian understandings of the conditions of aesthetic judgement and the emergence of those thinkers in the seventeenth and eighteenth centuries who began to focus on the psychology of aesthetic experience. Following these thinkers and further developments in the early part of the $20^{\text {th }}$ century, the work of John Dewey explored the psychological nature of what he called "an experience" in the field of education more generally (p.42). This article will also privilege the notion of aesthetic experience but will, more specifically, focus on an exploration of ideas borne out of aesthetic experiences that cultivate sociological questions about representation and the 
nature of cognitive and embodied engagement in classroom drama. Key to my view of dramatic representation is the notion of a provoked imagination.

In the $19^{\text {th }}$ century, Archibald Allison (1812) claimed that it was the imagination that was responsible for what we term "aesthetic experiences". Earlier philosophers of aesthetics had determined that the mere presence of beauty could create an aesthetic experience, but Allison insisted upon the "exercises of the imagination" in his understanding of aesthetic experiences. Contemporary writers in the field of arts education have also favoured this more active conception of aesthetic responses, such as the formidable Madeleine Grumet and Maxine Greene. They, and others, will be cited here, in support of a conception of "aesthetic experiences" in the drama classroom as active, selective, and highly framed experiences.

\section{Dramatic Texts and Aesthetic Knowing: Framing the Experiences}

One can hardly discuss the idea of aesthetic exploration without first engaging with the rather unwieldy idea of "creativity". Radford (2004), citing Margaret Boden, puts forward a very helpful notion of creativity as "conceptual space" (p.53). This "conceptual space" is what I will refer to as "the frame" carefully placed around dramatic learning, usually by a highly skilled teacher. Frequently because of this frame, something entirely forgettable to students is shaped into something worth considering. The "frame", therefore, consists of both careful pedagogical planning and, in many cases, a piece of text that ignites the conceptual space and inspires a deliberate probing. This deliberate probing, or what Radford might call creative thought, invites co-creators to "play at the boundaries of sense" (p.53). Bruner (1986) speaks about the "creative act" as bringing about a "shock of recognition", or what Radford equally describes as something speaking 
to something "within us". This idea is particularly helpful in deconstructing what is often at work in a collaborative piece of improvised drama activity in a classroom of young people.

To this end, I would like to offer three brief episodes as examples of textual and improvised drama engagement that speaks to Bruner's and Radford's ideas of "recognition", or resonance with "something within us" and to my own understanding of how ideas of representation or mimesis are operating in moments of aesthetic knowing for young people. The other principle at work, seemingly at odds with these ideas, is the notion of distance or alienation from an event, in effect a dis-identification. What I would especially hope to demonstrate in the following brief, empirical examples drawn from drama classrooms, is how the dramatic "frame" serves to distance the players from the subject in such a way as to ultimately engage them aesthetically and offer to them a simultaneous sense of recognition and the potential for change.

\section{Episode 1}

Works of art can never be realized by a merely passive attention. There has to be an active, energetic reaching out. (Greene, 2001, p. 182)

In my current ethnographic study of four urban drama classrooms in Toronto, Canada, and New York, USA ${ }^{1}$, I have observed the dramatic engagement of high school students through a wide variety of framing devices and textual engagements. In one of the Toronto sites, I interviewed a group of grade 11 (16-year old) drama students about some improvisation work they had done that was inspired by a story of a young pregnant 
teenage-girl who ended up in a group home for troubled youth. I remember the moment well when the teacher asked for a volunteer to be "hot-seated"2. A large, confident, male student volunteered to "play" the pregnant 15-year old girl. The class screamed with excitement when the teacher allowed him to take the "hot-seat" in the middle of the room. No one knew what would follow but all seemed to be anticipating a comical, perhaps mocking, performance. What followed, of course, surprised everyone. The young man who took on the role and sat in a chair in the middle of the room, listened carefully to the questions and responded with a profound, and unexplainable, recognition/identification, that had clearly been unforeseen by all present. Several weeks later, I would ask the group of students in a focus group discussion how they remembered that day in class:

Kathleen: You've just made me think of something else: remember when we first came into your classroom, and... you guys were doing role-playing? And people went up and sat in the chair, and you were performing different roles from a drama that you were doing, that you did before we came, about a pregnant girl in a home, or something like that? Remember that?

"Yeah" from the group.

Kathleen: Remember Jake played... the pregnant girl?

Sam: Yeah.

Kathleen: Okay...[some snickers from the group]. My memory is... that he was really good. That his improvised performance was a really good... a really effective interpretation. And, he's this big guy, and he's playing a pregnant girl. But, nobody laughed. That's my memory. Why was that? Why did people take that seriously, if that is actually what was going on?

\footnotetext{
${ }^{1}$ Gratitude to the Social Sciences and Humanities Research Council of Canada for their support of the study, now in its third year, titled, Drama Education, Youth and Social Cohesion: (re)constructing identities in urban contexts.

${ }^{2}$ This is an improvisational structure in drama that invites a student to be interrogated in-role as a character within the unfolding drama. Dramatic time stands still while teacher and students alike ask questions of the "character" in order to further develop the context, narrative and character(s) of the improvised story.
} 
Everyone in the group begins speaking at once.

Allissa: Because he was... acting good [sic].

Stuart: That was... like, a... Emmy-winning performance right there.

$\mathrm{K}: \mathrm{He}-\mathrm{he}$ what?

Stuart: That just slapped everyone in the face. That performance... That was like, a... Oscar-winning performance right there. Like... he just did it. I was, like "Whoa."

Alissa: Yeah, he was right... into the role.

Alissa \& Venus: He took it seriously.

Sam: Yeah, certain people just -

Venus [interrupting]: And also, it's not... being... uh... a young girl that's pregnant is nothing to... laugh at. Because... people probably... like, thought of it seriously, and... didn't - they didn't think it funny. They didn't think it was funny. So, like... everyone took it seriously.

Kathleen: What were you going to say, Sam?

Sam: Certain people just take initiative like that. They know how... they... like... It kind of shows... it kind of shows to some girls that, like... guys do know how to, like... they know how to take certain things serious [sic].

What is so interesting about this unpacking of their drama world is not only that we, as audience, were surprised by Jake's ability to "recognize" or possibly identify with something about the plight of the young woman and authentically depict it in his embodiment of the role, but that the drama structure had given him enough cognitive "distance" from whatever his own private moment of recognition was in order to publicly "perform" the artistic moment. What has further become clear about this classroom episode is that for Sam, the last student to speak, this was a moment of aesthetic representation that "spoke to him"; a moment in which a new kind of masculinity was permitted into the normally heavily rule-governed space of acceptable performances of masculinity, both in the fictions students undertake and the "real", social performances of 
masculinity: ...It kind of shows... it kind of shows to some girls that, like... guys do know how to, like... they know how to take certain things serious [sic]. At the very least, this moment was important for Sam because it was a representation of masculinity that was real for him; a different masculinity was imagined in that space, a new imaginary provoked, and it resonated with Sam in, what was for him, a noteworthy way. It is in this analysis that I return to the "sociology of aesthetics"; a concept germane to my understanding of the drama classroom: One person's aesthetic engagement is, more often than not, intimately tied to another's in the collective enterprise that is improvised drama.

If we borrow from the thinking of two theorists of the stage to further understand what might have been going on in this creative act, the architect of Method Acting, Anton Stanislavsky, would suggest that Jake had found something of the character in himself, something profound with which to identify (recognize) in order to render the character of the young girl, truthfully. Operating from a very different set of assumptions, the architect of epic theatre form, Bertold Brecht, would argue that rather than identifying in any affective way, the necessary distance was created in order for Jake (and those watching him) to appreciate, think about, and analyze clearly the actions of the character and her (and by extension Jake's) impact on the story. The creative act and the aesthetic engagement in that classroom, on that day, could be explained, therefore, in (at least) two very different ways, but what remains consistent in both accounts is the collective exercises of the imagination in which both Jake and the active classroom observerparticipants were involved; each intimately tied to the other, gaining from solo journeys made more compelling by the generative interaction of the group. 


\section{Episode 2}

And she's hanging out on a Friday night in November, 1997-- the moon is full, the air is clear. Usually the stars get lost in winter here. But on this night the stars are out, everyone is out, under cover, passing a joint, drinking vodka and sprite mixed in a can. Some are watching the sky and waiting because a Russian satellite is going to break through the earth's atmosphere tonight, right over Victoria. It will explode, light up all that black. But this girl, this regular girl and one other girl are waiting for something else; they are waiting to teach someone a lesson. They've already phoned her up, they've called her out. Because she is big, because she likes that boy. Because she is brown and she lost their book, because she doesn't fit and she lies. Because they can. (The Shape of a Girl, Joan McLeod, 2001. p. 49)

My second example of dramatic textual engagement comes from a workshop I conducted for a group of grade seven and eight students (11-13 years old) from the Toronto District School Board. In this workshop I was attempting to frame their engagement with some text from Joan McLeod's play, The Shape of a Girl. The play was inspired by the terrible true story of a 14-year old South Asian school-girl, Reena Virk, who was beaten and killed by a gang of girls and one boy in Victoria, Canada in 1997. The workshop was designed to help students think differently about the bullying issue and, further, to reconstruct the position of the "bystander" in the hope that young people might be better able to think through ways to effectively confront moments of bullying in their own and others' lives. Rather than being a remedial or "how to" kind of workshop, I sought to exploit the structures of drama to help us all struggle to understand- through exploration and performance of our own stories- the nature of conflict and our part in it.

The play, itself- the fiction- is about a girl called Bradie who is contemplating her own peer group and the kinds of exclusions and harassment that go on there. Braidie's story sits uncomfortably against the backdrop of the true story of Reena Virk and both of 
these stories provoke the context in which we explored our own stories. Pushing further, then, this 'once-removed', metaphoric space of theatre, I asked the group of 40 young students to begin to think about the stories of exclusion that they knew from their own lives. It is always fascinating for drama educators to see where students will take an instigating piece of text, to see how they will relate to it and make it their own. In smaller groups of five, I then asked the young people to create a very brief scene depicting a moment of exclusion in order for us to examine it. A group of five young boys got quickly to work and soon asked me whether they were allowed to swear in their scene. I told them it was permitted if it was integral to their scene; in other words, I would hold them responsible for their choices. Standing near the group, I quickly realized that this particular group of boys was preparing to depict a graphically violent scene of a gaybashing. They were hurling insults at one small boy who volunteered to play the victim. In these brief moments of "rehearsal", I was wondering how I might ultimately help the whole group and these young boys, themselves, to respond ethically to what would decidedly be an explicitly homophobic scene. Somewhere between my viewing of their brief rehearsal and the time to share their work, the boys made a decision to change, entirely, the premise of the story. When it came to showing it to the whole group, the outcast was no longer a "fag" but a severely mentally challenged person. At the end of the performance of their very disturbing scene, I turned to the whole group and asked them why it had been so difficult for us to watch this scene. After a long silence, one girl raised her hand and replied: "Because he was excluded for a way that he was born". As one might imagine, we went on to have a very rich conversation about how exclusion 
operates, how relations of power operate through it, and ultimately how incidents of exclusion are rule-governed and enabled by passivity.

The point of this episode is to say that we were certainly not engaged by a beautiful nor a pleasurable experience but that there was an aesthetic and experiential knowing that was drawn out, in the first instance, by the students' engagement with the dramatic text, and in the second instance, by our reactions as audience to the scene. The group of boys spoke the words in the passage cited above but layered in their own story of exclusion. I can only speculate here that the gay-bashing scene originally planned was too dangerous and not, perhaps, at enough distance from the actual lives of these young boys. This text of a girl beaten by a gang of girls and one boy, soon became a story of a gay boy beaten by a group of boys, which, ultimately became the story of the kind of outsider that no one in that group could potentially "identify" with or perhaps more importantly, be mistaken for.

Fenner (2003) describes three kinds of associations, which may be at work in an aesthetic experience. They are: Recollective, Emotional, and Cognitive. It would seem that degrees of all three kinds of associations were at work for different students at different moments in their workshop performances. The performing boys explained to us, in the post-scene discussion, that they were recollecting an actual event that they had witnessed. The actual event, however, involved a gay boy but in their performance this day, they clearly "[thought] about the object under consideration, [and transferred it] to another object or event that shares some property with the first" (p.46).

If Fenner is right when he posits that "aesthetics is about the sensuous aspects of our experiences" (p.41), he is in agreement with northern Irish playwright Brian Friel, 
who in an essay in 1967 pondering the point of the arts and particularly the function of the theatre comes back to the central question of how we frame our lives through art and how we come to know the world aesthetically. For him, the beautiful and the ugly- all the sensuous aspects of our experiences- equally weave the tapestry of human life:

What function have they, then? They have this function: they are vitally, persistently, and determinedly concerned with one man's insignificant place in the here-and-now world. They have the function to portray one man's frustrations and hopes and anguishes and joys and miseries and pleasures with all the precision and accuracy and truth that they know; and by so doing help to make a community of individuals. They have this function - their supreme function, I think, and one they share with all groping, trumpeting artists everywhere and at all times, and it is this: that they recognize with great clarity the conflict between the world of the flesh and the world of the spirit, or if you dislike the terms, the world of the physical and the world of the cerebral. And when they depict in mean, gruesome detail only one portion of our existence, perhaps in this generation the dominant portion, they are crying out for recognition of the existence of something less ignoble, something more worthy. They are asking us to recognize that even in confusion and disillusion, strength and courage can exist, and that out of them can come a redemption of the human spirit (in Murray 1999, p.24).

We are again, I'm afraid, in the territory of the imaginary and for that, I need now turn to notions of aesthetic engagement and its relationship to the peculiarities of drama pedagogy.

\section{The Aesthetics of Dramatic Engagement}

Celebrated French-Canadian theatre director Robert Lepage suggests that there are two ways to tell a story: a metaphorical way and a metonymical way. Metonymy is a horizontal telling - a beginning, middle and end - with things happening in a certain order. But a metaphorical telling is about the layers or vertical levels of a story. Film or 
television, he suggests is metonymical; we watch the story unfold across the horizon.

Theatre, however, tells its story in the vertical sense:

It's vertical on many levels in the sense that I think theatre has a lot to do with putting people in contact with the gods, whatever that means. That's where theatre comes from. Plays were written in a vertical manner about human aspirations... There is a sense of spirituality in theatre: it's a medium that you could use to talk about spirituality, about spiritual quests. Of course, there's a reason why film has a horizontal frame; because cameras pan and cinema is all about everyday life and realism. Being at that level it goes from left to right, or right to left. Sometimes it does pan up and down, but in general horizontal stories are better told with film. Maybe the shape and frames of film will all change one day. But why hasn't anybody invented a vertical screen after a century of cinema? The medium technically and symbolically is about the horizon, the land on which human beings work and walk (144).

In addition, then, to the equal parts "rapprochement" and "distancing" that I have used to qualify aesthetic engagement in Section II, I will use here a further empirical episode to illustrate the intermingling of the "spiritual" and the "material", or the cognitive and embodied so often the markers of aesthetic engagement in drama or what I have referred to in this article as the sociology of aesthetic engagement in drama education.

\section{Episode 3}

The practical knowledge that we bring with us from home remains trapped in memory coded in images, sensory associations, stories, and emotions. Lodged in intuition, this practical knowledge is rarely extended to our work in the public world because it is rarely resymbolized through processes that encode it for reflection and translation to other settings. (Grumet, 1991, p. 75)

In a four-day workshop with drama educators and theatre practitioners in Budapest Hungary in November 2004, I, once again, structured for aesthetic engagement with Joan 
McLeod's text The Shape of a Girl. The following passage was used as a departure point for the exploration of social exclusion encountered by young people in Hungary. Attention to this pervasive issue through the use of drama has been identified by the Hungarian Ministry of the Interior as a great priority and a first-step toward a more comprehensive and effective approach to crime prevention. I was invited to help the teachers/theatre practitioners explore the potential of aesthetic engagement and drama pedagogy in order to bring analytical sophistication to this pressing social issue. I shared the following piece of text with the participants:

We are amazed by Sofie, how she can spend hours, entire afternoons down there on all fours. How she never cares about who sees. Good little horsie. That's what Adrienne says and then Adrienne is flying, having been bucked by Sofie the horse onto the couch. And then Rachel has a turn on Sofie's back and Sofie sends her flying too. We love Sofie the horse. We make tiny braids all over her head; we paint rainbows on her cheeks.

And then one day, one normal un-special day, Adrienne comes to school and announces that it's penalty day. We don't know what penalty day is. Adrienne explains that on penalty day one girl is chosen and everyone is mean to that one girl for the whole day. Why? Adrienne doesn't know. It's just a part of school. Adrienne offers to go first. We get to be mean to her first. I want to go first too. At first, penalty day is hard to figure out. There are a lot of rules. The person we have to be mean to has fleas of course. Everyone has to write FP for flea proof on their hand.

Braidie, as a teenager again.

You know something Trevor? By the end of grade four penalty day had become as complex as World War Two. But who the enemy was had become entirely simple. Now all the girls had FP written on their hands, all the girls but one. I don't know why it was Sofie. It just was. (The Shape of a Girl, Joan McLeod, 2001. p. 30-31)

Once again, soliciting both the "real" and the "imaginary", I invited the participants to share their own theatrical snapshot of "penalty day". With this, we would again have a basis for improvised exploration and imaginative probing of the issues at stake. This time, a group of women presented their brief scene at the end of which I entered into the scene- in role- as an interrogator of the events that had transpired in the scene. In brief, 
one young person had been excluded in a classroom situation by a group of students. It was a rather unremarkable sketch of a problem we all easily recognized. The scene itself was helpful in depicting the nature of exclusion but it was aesthetically thin. When I entered the scene, I felt I would have to work hard to move all of our imaginations beyond the stereotypes we had seen and arrive somewhere closer to Fenner's Recollective, Emotional and/or Cognitive aesthetic engagement. While the facilitation of the drama teacher is obviously important, what is more important here is that the "built up" context and the improvised development of the characters leave open spaces for unpredictable engagement, for those moments of identification, unknowable to the teacher, that a player might make with the fiction. The teacher is simultaneously working toward creating a fictional context that provides the critical distance for the role-player (and those watching) to scrutinize and imaginatively 'play with' the possible actions and responses.

In role, I ask the group of would-be students why they had excluded this particular student and they tell me, convincingly, that she is older than the rest of them and shouldn't be in their grade; that she is a loser, a loner, does not "fit in". I ask the woman playing the excluded young person what is going on and she proceeds to tell me that she is excluded, even bullied, by the teacher in the classroom and the others are simply following her lead. I ask if it is true that she is older than the other children and she says yes and that her father is going to come into the school and beat up the teacher.

It is here where the cultural, political, and material context escapes me as facilitator. It is only in an illuminating conversation much later with my translator that I am able to fully comprehend the powerful aesthetic engagement that followed in our 
improvised work together. The words alone, despite the skill of my translator, could not help me understand that the people in the room were Hungarian from Hungary, Transalvania, Serbia-Montenegro, Romania and the Ukraine. I did not know that $5,000,000$ of the 15,000,000 Hungarians in the world had lost their citizenship when borders were re-drawn. I did not know that the Hungarians in the room, living in Hungary, would vote in a referendum in one week's time to decide whether Hungarian citizenship should be extended to those Hungarians who now found themselves outside re-drawn borders, whose minority status in their "new homes" was a source of shame and exclusion. I did not know that the role-playing "excluded student" was one of those awaiting her fate in the upcoming referendum. Naturally, these were identifications and symbolic allusions that I could not read as a foreigner but they did explain the rather sudden depth of engagement and theatrical/aesthetic sophistication that followed. What I would also not fully appreciate until later was that the aesthetic coding that the "excluded student" role-player engaged in was a distancing mechanism in order to allow herself the necessary distance from which to respond to the unfolding fiction. The "fact" of being a grade behind for her age and having a father who would come in to "beat the teacher up" was nothing other than a subtle piece of signing to her co-improvisors that she was a "gypsy", a "Roma". Like the boys who depicted the mentally challenged excluded character in their scene, these women also presented an "outsider" who was not present in our drama classroom; they chose subjectivities at enough distance from "our" lives that we could, therefore, critically engage with the story and the social positions represented therein. 
The loss of place for practical knowledge in the public sphere for which Grumet mourns is, here, no longer lodged in intuition, nor relegated to the margins, but "resymbolized through [dramatic] processes that encode it for reflection and translation to other settings" (p.75).

\section{Conclusion}

We have no word in the English language that unambiguously includes what is signified by the two words 'artistic' and 'esthetic'. Since 'artistic' refers primarily to the act of production and 'esthetic' to that of perception and enjoyment, the absence of a term designating the two processes taken together is unfortunate (Dewey, 1934, p.48). While the word “drama”, in itself, might not solve Dewey's conundrum, drama education is the art form that I think comes closest to making good on both the "artistic" and the "aesthetic" processes about which Dewey is speaking. In drama, the perception, "enjoyment" and discovery of it is indistinguishable from the creative act itself; rarely are these seen as separate processes. Dewey goes on to explain that art denotes a process of doing or making. Esthetic, by contrast, refers to experience as appreciating, perceiving, and enjoying; it denotes the consumer's rather than the producer's standpoint. The unusual thing about drama education, it must be said, is that it cannot separate out the doing from the perceiving. Both are working simultaneously as the artist/maker plays audience to his/her own (and others') creations.

In drama, aesthetic knowledge hinges on perception and interpretation. And, as the episodes of this article hopefully illustrate, the collaborative nature of drama allows 
the perceptions and interpretations of the players to join various other perspectives with their own. Eisner argues that "the common function of the aesthetic is to modulate form so that it can, in turn, modulate our experience. (1998, p. 34). The form of dramatic engagement allows for new representations, new explorations of language and meaning. And these are often emotional and perceptual, in addition to cognitive, types of language that expand meaning (see Eisner 1998; Rorty 1979).

To return to my initial idea of the provoked imagination, I hearken, as Connell (2000) did, Louise Rosenblatt's 1938 book, Literature as Exploration, in which she says that if readers are allowed to fully respond to a book rather than just receive it, they "participate in the experiences of others, develop a sense of the complex fabric of our society, extend beyond the provincialism of time and space, and create an awareness of possible alternatives that can serve as a liberating force in their thinking” (p. 192-193). Connell summarizes that an aesthetic experience makes room for people's prior beliefs and experience, thus allowing them to connect emotionally and stimulate the imagination. In other words, an aesthetic experience- like the structure of drama education itselfresides in the connection between what a person already knows, feels, and desires and what a new experience might offer. Connell concludes that what distinguishes an aesthetic experience from a nonaesthetic one is the degree to which the imagination is stimulated (Connell, 2000, p. 33). And what greater example of an "exercise of the imagination" than drama's willful acceptance of an unreality that stands alongside our realities?

I have long been persuaded that the kinds of representations of self/other that dramatic engagement provokes ought be seen as a necessary staple of social education. 
Explorations of the aesthetic, through drama, open up for children what is possible, what is knowable, and what may be just beyond their grasp. I have argued before (Gallagher 2000) that it is the responsibility of schools to prepare students for the richness of living, and one way to do this is to include aesthetic experiences in their learning, without which they will surely have impoverished images of human progress, in all its splendour and misery. This brief examination of the sociology of aesthetics in drama practice has aimed to explore the territory of the imagination that is at once proximal to and distant from the actual world and lives of the players. I have attempted to illustrate that one of the significant ways in which the players of drama engage aesthetically is through critically examining and physically embodying their own and others' sensuous perceptions and interpretations of a shared world. 


\section{Works Cited}

Alison, A. (1812) Essays on the Nature and Principles of Taste. Boston:

Cummings and Hilliard.

Bruner, J. (1986) Actual Minds, Possible Worlds. Boston: Harvard University Press.

Connell, J. (2000) Aesthetic Experiences in the School Curriculum: Assessing the Value of Rosenblatt's Transactional Theory. Journal of Aesthetic Education, Vol. 34, No. 1: 27-35.

Delgado, M. M. and Heritage, P. (eds.) (1996). In Contact with the Gods: Directors Talk Theatre. (pp. 129-157). Manchester and New York: Manchester University Press.

Dewey, J. (1934). Art as Experience. New York: G. Putnam's Sons.

Eisner, E. (1998). The Kinds of Schools We Need. Portsmouth, NH: Heinemann.

Fenner, D. E. W. (2003). Aesthetic Experience and Aesthetic Analysis. Journal of Aesthetic Education, Volume 37, No. 1: 40-53.

Gallagher, K. (2000) Drama Education in the Lives of Girls: Imagining

Possibilities. Toronto, London, Buffalo: University of Toronto Press.

Greene, M. (2001) Variations on a Blue Guitar. New York: Teachers College Press.

Grumet, M. (1991). Curriculum and the Art of Daily Life. In G. Willis and W. Shubert (eds.) Reflections from the Heart of Educational Inquiry: Understanding Curriculum and Teaching through the Arts (pp. 74-89). Albany, N.Y.: State University of New York Press. 
McLeod, J. (2002) The Shape of a Girl. Vancouver, B.C.: Talonbooks.

Murray, C. (1999) (ed.) Brian Friel: Essays, Diaries, Interviews 1964-1999.

London and New York: Faber and Faber.

Radford, M. (2000) Emotion and Creativity. Journal of Aesthetic Education, Vol. 38, No. 1: 53-64.

Rorty, R. (1979). Philosophy and the Mirror of Nature. Princeton, N.J.: Princeton University Press.

Rosenblatt, L. (1938). Literature as Exploration (reprint). New York: Modern Language Association. 